\title{
PROTOTYPE GROUNDING DETECTOR PADA GROUND CLUSTER DENGAN SISTEM INTERLOCKPADALBS (LOAD BREAK SWITCH) BERBASIS ARDUINO MEGA 2560 DENGAN TAMPILAN HMI (HUMAN MACHINE INTERFACE)
}

\author{
Bambang Handoko Pasaribu, Iman Setiono \\ Program Studi Diploma III Teknik Elektro \\ Sekolah Vokasi Universitas Diponegoro \\ Correspondent author : imansetionoms@gmail.com
}

\begin{abstract}
Bambang Handoko Pasaribu, Iman Setiono, in this paper explain that electricity has become a daily necessity in the community both social, economic and business. Therefore electricity is needed every day and it is the reliability of PLN. To fulfill such reliability While the reliability of electrical energy should be followed by inspection on the equipment used. PLN field employees themselves who every day always do inspection on the network of all the repeaters, so that field officers always know the state of the network in the field. If the network looks bad or requires maintenance it will be scheduled to do the job. Before the holding of the work it will be done in the first outage area is to operate the switching tool didaerah area. The switching tools are ABSW and $L B S$. After all the swithing tools are operated the workers always do the grounding first on the three phases by using ground clusters at the starting point to the end of the work where if transmitted so called PMS ground. This is done as a safety because the LBS switching tool is closed so that workers are not sure if the network has been extinguished and as a safety if LBS failed to work or failure. But here the worker himself sometimes still not sure whether the ground cluster is already installed properly or not. And as a safeguard against the occurrence of any maneuvering done by employees from the office Rayon. Therefore the author wants to make a prototype to detect whether grounding is installed properly or not in every phase. The prototype uses Arduino mega as its micron and uses a voltage sensor to find out the value of the voltage. If the ground claster is installed and work fails on LBS then the OCR relay will work and PMT will trip. With the prototype is expected to improve security in the work and minimize the occurrence of work accidents. This prototype has a $0 \%$ chance of a crash if the ground cluster is properly installed.
\end{abstract}

Keywords: Arduino Mega, Ground Detector, OCR relay, Voltage Sensor.

PENDAHULUAN

Latar Belakang

Keberadaan listrik saat ini sangatlah dibutuhkan oleh setiap manusia dalam kehidupan modern, antara lain untuk keperluan sosial, ekonomi dan bisnis. Semakin banyak pelanggan yang harus dilayani oleh PLN, haruslah diikuti dengan kehandalan energi listrik yang disalurkan. Sedangkan kehandalan energi listrik haruslah diikuti dengan inspeksi pada peralatan-peralatan yang digunakan. Pegawai lapangan PLN sendiri yang tiap hari selalu melakukan inspeksi pada jaringan seluruh penyulang, sehingga pegawai lapangan selalu mengetahui keadaan jaringan dilapangan. Jika jaringan terlihat tidak baik atau memerlukan pemeliharaan maka akan dijadwalkan untuk melakukan pekerjaan. Sebelum diadakannya pekerjaan maka akan dilakukan pemadaman terlebih dahulu didaerah tersebut yaitu dengan mengoperasikan alat switching didaerah tersebut. Alat switching tersebut ialah ABSW, LBS dan Recloser. Setelah semua alat swithing dioperasikan pekerja selalu melakukan grounding terlebih dahulu pada ketiga fasa dengan menggunakan ground cluster dititik awal hingga titik akhir pekerjaan. Hal tersebut dilakukan sebagai pengaman dikarenakan alat switching LBS atau Recloser yang tertutup sehingga membuat pekerja belum yakin jika jaringan tersebut sudah padam dan sebagai pengaman jika LBS gagal kerja atau failure. Namun disini pekerja sendiri terkadang masih belum yakin apakah ground cluster tersebut sudah terpasang dengan baik atau belum. Dan sebagai pengaman agar tidak terjadinya salah manuver yang dilakukan oleh pegawai dari kantor APD.

\section{LANDASAN TEORI}

\section{Sistem Tenaga Listrik}

Sistem tenaga listrik adalah sekumpulan pusat-pusat listrik yang di interkoneksi satu dengan lainnya, melalui transmisi atau distribusi untuk memasok ke beban atau dari satu pusat listrik dimana mempunyai beberapa unit generator yang dipasang paralel. (Wahyudi Sarimun: 2014)

Pada dasarnya sistem tenaga listrik memiliki 3 unsur. Unsur yang pertama adalah pusat listrik (pembangkit), dimana terdapat generator yang dapat menghasilkan energi listrik Tegangan yang dihasilkan oleh pusat listrik itu biasanya merupakan tegangan menengah (TM). Kedua, sistem penyaluran listrik. Pada sistem ini terbagi menjadi saluran transmisi dan sistem distribusi. Saluran transmisi merupakan penyaluran energi listrik dari pusat pembangkit menuju gardu induk yang 
menggunakan tegangan tinggi karena jaraknya yang jauh supaya pasokan tenaga listrik tetap stabil terutama tegangan dan frekuensi. Saluran distribusi merupakan penyaluran energi listrik dari gardu induk menuju beban yang terbagi atas saluran distribusi primer dengan tegangan menengah (TM) dan saluran distribusi sekuder dengan tegangan rendah (TR). Keempat, adanya unsur pemakaian atau utilisasi, yang terdiri dari instalasi pemakaian tenaga listrik. Instalasi pemakaian tenaga listrik industri biasanya menggunakan tegangan menengah (TM) maupun tegangan tinggi (TT). Sedangkan untuk pemakaian tenaga listrik rumah tangga menggunakan tegangan rendah (TR).

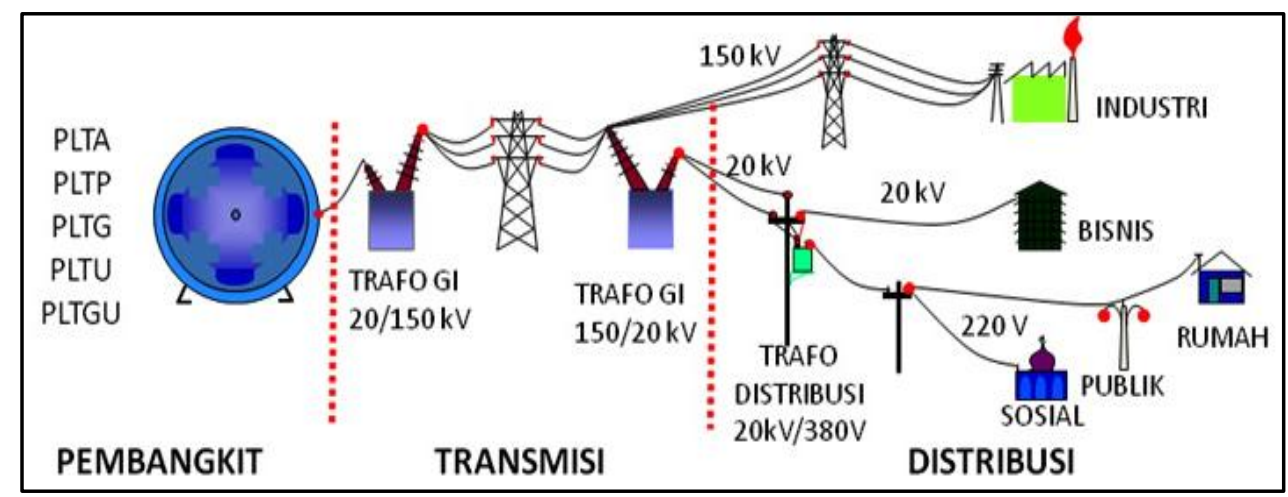

Gambar 1. Jaringan sistem tenaga listrik

\section{MIKROKONTROLER Arduino Mega 2560}

Arduino adalah kit elektronik atau papan rangkaian elektronik open source yang di dalamnya terdapat komponen utama yaitu sebuah chip mikrokontroler dengan jenis AVR dari perusahaan ATmel.

Mikrokontroler itu sendiri adalah chip atau Integrated Circuit (IC) yang bisa diprogram menggunakan komputer. Tujuan ditanamkannya program pada mikrokontroler adalah supaya rangkaian elektronik dapat membaca input, kemudian memproses input tersebut sehingga menghasilkan output yang sesuai dengan keinginan. Jadi mikrokontroler berfungsi sebagai otak yang mengatur input, proses, dan output sebuah rangkaian elektronik.

Arduino Mega 2560 adalah papan mikrokontroler berbasiskan Atmega 2560 yang memiliki 54 pin digital input/output, dimana 15 pin diantaranya digunakan sebagai output PWM, 16 pin sebagai input analog, 4 pin sebagai UART (port serial hardware), sebuah osilator kristal $16 \mathrm{MHz}$, koneksi USB, jack power, header ISCP, dan tombol reset.

Gambar 2 adalah tampilan board Arduino Mega 2560. Dan tabel 2.1 menunjukkan spesifikasi dari Arduino Mega2560.

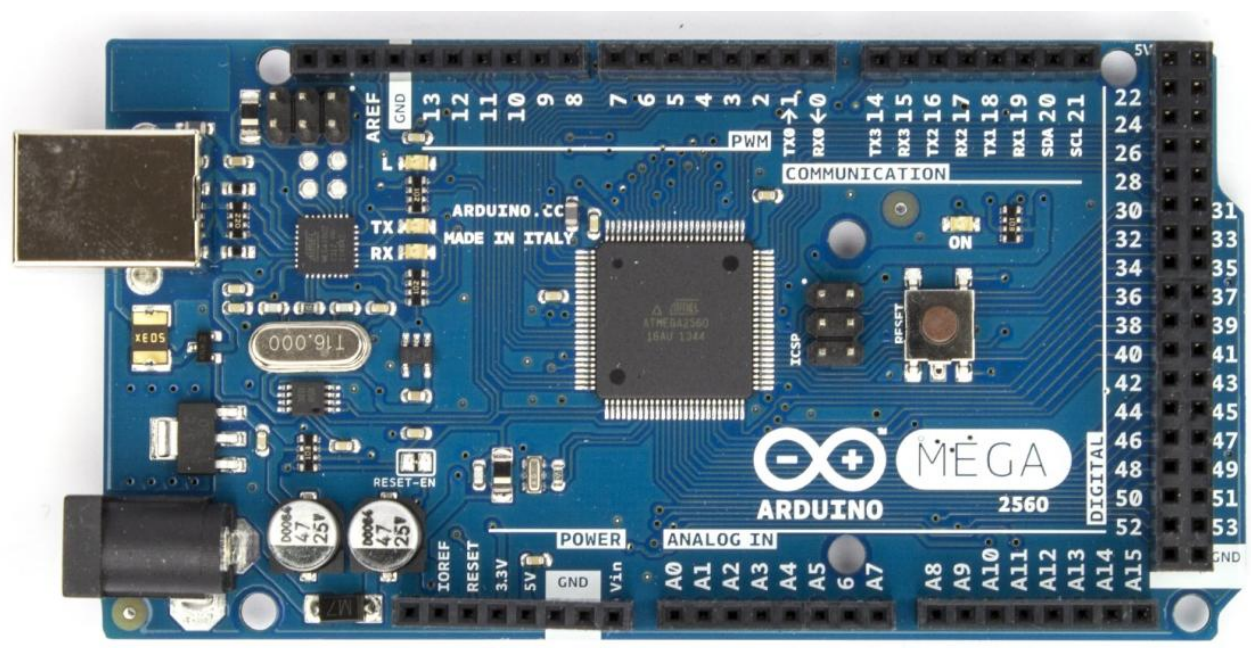

Gambar 2. Tampilan board arduino Mega2560 
Tabel 1. Spesifikasi dari Arduino Mega 2560

\begin{tabular}{|l||l|}
\hline Mikrokontroler & ATmega2560 \\
\hline Tegangan Operasi & $5 \mathrm{~V}$ \\
\hline \hline Input Voltage (disarankan) & $7-12 \mathrm{~V}$ \\
\hline Input Voltage (limit) & $6-20 \mathrm{~V}$ \\
\hline Pin Digital I/O & 54 (yang 15 pin digunakan sebagai output $\mathrm{PWM})$ \\
\hline \hline Pins Input Analog & 16 \\
\hline \hline Arus DC per pin I/O & $40 \mathrm{~mA}$ \\
\hline Arus DC untuk pin 3.3V & $50 \mathrm{~mA}$ \\
\hline \hline Flash Memory & $256 \mathrm{~KB}$ (8 KB digunakan untuk bootloader) \\
\hline SRAM & $8 \mathrm{~KB}$ \\
\hline EEPROM & $4 \mathrm{~KB}$ \\
\hline \hline Clock Speed & $16 \mathrm{MHz}$ \\
\hline
\end{tabular}

\section{BLOK DIAGRAM SISTEM}

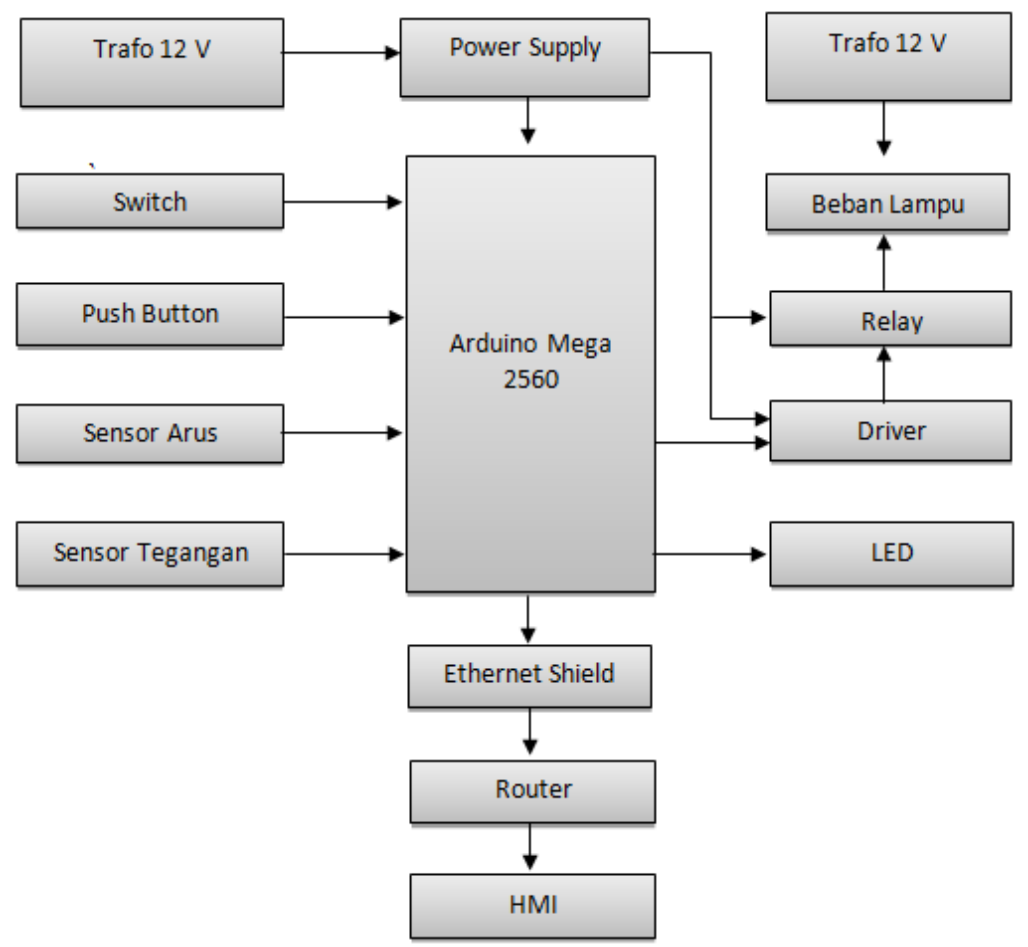

Gambar 3 Blok Diagram Keseluruhan

Suatu sistem memiliki tiga unsur utama, yaitu masukan (input), proses, dan keluaran (output). Berdasarkan blok diagram di atas, maka ketiga unsur utama dalam sistem dapat dijabarkan sebagai berikut:

- Komponen yang digunakan sebagai masukan pada mikrokontroler Arduino Mega 2560 adalah catu daya, push button, switch, sensor arus dan sensor tegangan.
- $\quad$ Mikrokontroler Arduino Mega 2560 berfungsi sebagai pengendali atau otak yang memproses masukan sehingga menghasilkan keluaran pada sistem.

- Sebagai piranti keluaran dari mikrokontroler, digunakan ethernet shield, router, relay, LED, dan $H M I$. 
PENGUJIAN

Tabel 2 Pengukuran Tegangan Prototype Jaringan Distribusi

\begin{tabular}{clc}
\hline No & \multicolumn{1}{c}{ Titik Ukur } & Tegangan Terukur \\
\hline 1 & $\begin{array}{l}\text { Tegangan Fasa R } \\
\text { (Section 2) }\end{array}$ & 0 V AC \\
2 & $\begin{array}{l}\text { Tegangan Fasa S } \\
\text { (Section 2) }\end{array}$ & 0 V AC \\
3 & $\begin{array}{l}\text { Tegangan Fasa T } \\
\text { (Section 2) }\end{array}$ & OV AC \\
\hline
\end{tabular}

Arus terukur pada PMT ketika pekerjaan dan telah dipasang ground cluster.

Tabel 3 Pengukuran Arus Prototype Jaringan Distribusi

\begin{tabular}{clc}
\hline No & \multicolumn{1}{c}{ Titik Ukur } & Tegangan Terukur \\
\hline 1 & $\begin{array}{l}\text { Arus Fasa R } \\
(\text { Section 1) }\end{array}$ & $0 \mathrm{~A}$ \\
2 & $\begin{array}{l}\text { Arus Fasa S } \\
\text { (Section 1) }\end{array}$ & 0A \\
3 & $\begin{array}{l}\text { Arus Fasa T } \\
\text { (Section 1) }\end{array}$ & 0 A \\
\hline
\end{tabular}

Arus terukur pada recloser ketika pekerjaan dan telah dipasang ground cluster.

\section{KESIMPULAN}

- Grounding Detector padaGround Clasterdiperlukan agar pekerja merasa nyaman ketika melakukan pekerjaan pemeliharaan jaringan distribusi.

- Sistem proteksi perlu ditingkatkan guna mengurangi kecelakaan kerja dilapangan.

- Prototype ini memiliki kemungkinan kecelakaan $0 \%$ jika ground cluster sudah terpasang dengan baik.

\section{DAFTAR PUSTAKA}

1. Alam, Aji Suryo. 2011. Pemeliharaan Pemutus Tenaga (PMT) Media PemadamBusur Api Gas Sf6 Dengan Penggerak SpringPT. PLN (Persero) P3B Regional Jateng dan DIYUPT. Semarang GI 150 KV Srondol. Laporan Magang. Semarang: Universitas Diponegoro.

2. Akbar, Fauzan Hafidz. 2016. Evaluasi Koordinasi Proteksi Feeder Ungaran 02 Di Wilayah Kerja PT PLN (Persero) Unit Layanan Salatiga. Laporan Tugas Akhir. Semarang : Universitas Diponegoro.

3. Ghani, Reza Muhammad. 2016, Alat Pendeteksi Terputussnya Aliran Listrik pada Jaringan Tegangan Menengah Satu Fasa Menggunakan Arduino Mega 2560 dengan Memanfaatkan Aplikasi Web. Laporan Tugas Akhir. Semarang: Universitas Diponegoro.

4. Oktaviyanto, Yoga Dwi. 2014. Pemeliharaan, Pengoperasian dan Pengkoordinasian
Recloser. Laporan Magang. Semarang: Universitas Diponegoro.

5. Pasaribu, Bambang Handoko. 2016. Proses Pembangunan Penyulang (Feeder) SRL 08 Guna Menanggulangi Penambahan Beban di SRL 01 Dan SRL 06 PT. PLN (Persero) Rayon Semarang Selatan. Laporan Magang. Semarang: Universitas Diponegoro.

6. Purnama Sari, Dea. 2014. Rancang Bangun Catu Daya Terprogram dengan Tampilan Arus dan Tegangan Berbasis Mikrokontroler. Tugas Akhir Terpublikasi. Palembang: Politeknik Negeri Sriwijaya.

7. Rahman, Fahmi Faisal. 2016. Pelimpahan Beban Jaringan Distribusi $20 \mathrm{KV}$ Berbasis PLC OMRON CP1E E20SDR-A Menggunakan Software CX-Programmer Guna Mengurangi Daerah Padam di PT. PLN (Persero) Rayon Semarang Barat. Laporan Tugas Akhir. Semarang: Universitas Diponegoro.

8. Sarimun, Wahyudi. 2011. Buku Saku Pelayanaan Teknik (Yantek). Depok: Garamond

9. Sarimun, Wahyudi. 2012. Proteksi Sistem Distribusi Tenaga Listrik. Depok : Garamond. 